\title{
On the effects of monitoring and control settings on voltage control in PV-rich LV networks
}

DOI:

10.1109/PESGM.2015.7285791

Link to publication record in Manchester Research Explorer

\section{Citation for published version (APA):}

Procopiou, A. T., Long, C., \& Ochoa, L. F. (2015). On the effects of monitoring and control settings on voltage control in PV-rich LV networks. In IEEE/PES General Meeting 2015 (pp. 1-5)

https://doi.org/10.1109/PESGM.2015.7285791

\section{Published in:}

IEEE/PES General Meeting 2015

\section{Citing this paper}

Please note that where the full-text provided on Manchester Research Explorer is the Author Accepted Manuscript or Proof version this may differ from the final Published version. If citing, it is advised that you check and use the publisher's definitive version.

\section{General rights}

Copyright and moral rights for the publications made accessible in the Research Explorer are retained by the authors and/or other copyright owners and it is a condition of accessing publications that users recognise and abide by the legal requirements associated with these rights.

\section{Takedown policy}

If you believe that this document breaches copyright please refer to the University of Manchester's Takedown Procedures [http://man.ac.uk/04Y6Bo] or contact uml.scholarlycommunications@manchester.ac.uk providing relevant details, so we can investigate your claim.

\section{OPEN ACCESS}




\title{
On the Effects of Monitoring and Control Settings on Voltage Control in PV-Rich LV Networks
}

\author{
Andreas T. Procopiou, Chao Long, Luis F. Ochoa \\ School of Electrical and Electronic Engineering \\ The University of Manchester \\ Manchester, UK \\ andreas.procopiou@manchester.ac.uk, \\ chao.long@manchester.ac.uk, luis_ochoa@ieee.org
}

\begin{abstract}
Adopting on-load tap changer (OLTC)-fitted transformers in low voltage ( $\mathrm{LV}$ ) networks can be a potential solution to counteract voltage rise caused by high penetrations of residential photovoltaic (PV) systems. To efficiently control the OLTC network monitoring might be considered. This work assesses the performance of a proposed OLTC control logic considering different remote monitoring schemes and control cycles. A Monte Carlo-based time-series analysis is applied to a real $U K$ residential $L V$ network considering different uneven PV penetrations per feeder. Results show that the adoption of monitoring only at the end of each feeder can provide a satisfactory performance of customer voltages (BS EN50160 compliant). Additionally, the proposed control logic with a 30minute control cycle can reduce the number of tap changes whilst producing a good voltage performance. The results can help distribution network operators determining the most adequate control approaches for OLTC-fitted transformers in future $L V$ networks.
\end{abstract}

Index Terms-- Low voltage networks, on-load tap changer, photovoltaic systems, voltage control, control settings.

\section{INTRODUCTION}

As a result of the incentives continuously rolled out in several EU countries, the adoption of small-scale photovoltaic (PV) systems has seen a significant growth in low voltage (LV) distribution networks. As PV systems are expected to reach higher penetration levels in the near future, technical issues such as voltage rise and thermal overloads will arise. Voltage rise is one of the dominant constraints that limit the LV network's PV hosting capacity [1].

In the UK, the last points where on-load tap changer (OLTC)-fitted transformers are used are primary substations (i.e., $33 / 11 \mathrm{kV}$ or $33 / 6.6 \mathrm{kV}$ ). Distribution network operators (DNOs) design LV circuits with off-load tap changers which limits the 'on load' flexibility to manage voltages close to the LV customers. The use of LV OLTC-fitted transformers has been recently studied in order to increase the flexibility of voltage management closer to LV customers [2-5].

In order to efficiently manage the busbar voltage and consequently the customer voltages, measurements across the
LV network are required to visualize its state. However, measurements in LV networks are typically non-existent and therefore information about the network state is not available. Consequently, remote monitoring at strategic points in the network can provide visibility of voltages close to the customers' connection points. Considering, however, the large number of LV networks around the world, it is crucial to understand the extent to which monitoring and its location can benefit the performance the OLTC-based voltage control. Additionally, depending on the adopted OLTC control logic, a high number of tap operations can lead to the OLTC wear and tear [2], therefore the effects of the corresponding control settings, such as control cycle, need also to be investigated.

In [3] the coordinated control of OLTC, adopting remote monitoring at critical end points, with reactive power compensation through PV inverters was studied in order to manage voltages in a typical German LV network (loads have three-phase connections). Although the results show that voltages can indeed be managed with such a control strategy, the work was limited only to some deterministic cases of a specific PV penetration level, hence not providing the full picture of potential scenarios. In terms of impacts, only voltage at a specific network point was quantified rather than considering all the voltages at customer connection points. In addition, no details were provided in terms of the number of required tap changes.

The adoption of LV OLTC-fitted transformers was studied in [4] considering a load-dependent adjustment of the voltage set-point, i.e., the OLTC set-point is changed according to the total load variation. To capture this relationship an accurate understanding of the feeder topology and impedances is required which makes the applicability of such a control algorithm less practical as it has to be tuned for each network.

Authors in [5] investigate the application of different control approaches such as the use of line drop compensation taking into account the effects of PV generation, and the use of remote monitoring devices to efficiently control a $\mathrm{LV}$ OLTC-fitted transformer. As expected, it was found that the
This work has partially been funded by EDF R\&D, France, through the EPSRC iCASE project "Active Management of LV Networks" 2013-2017, and by Electricity North West Limited (ENWL), UK, through the Ofgem's Low Carbon Networks Fund Tier 1 "Low Voltage Integrated Automation (LoVIA)", 2014-2015. 


\section{Accepted Paper}

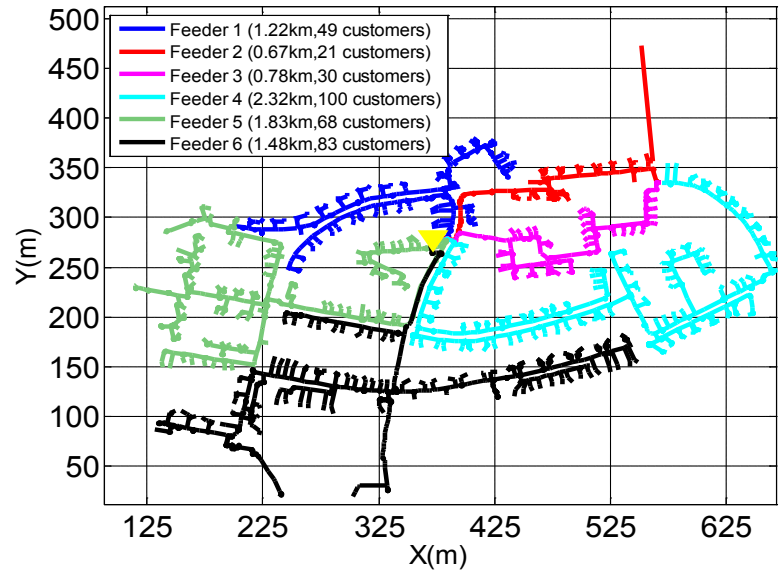

Fig. 1 Real UK LV Network - Topology and general characteristics

higher visibility provided by monitoring devices (i.e., voltages) can offer a better voltage regulation through the OLTC. Although, the approach shows promising results, no detailed analysis in terms of the locational effects of remote monitoring was carried out. Furthermore, this deterministic analysis, considering only one PV penetration level, did not assess the impacts of control cycle lengths and the corresponding quantification of tap changes.

In this work, a flexible OLTC control logic is proposed. Its performance is assessed considering three different remote monitoring schemes (i.e., middle, end and middle \& end points of each feeder) and four different control cycles (i.e., 1, 10, 20, 30 minutes). A Monte Carlo methodology previously developed in [6] considering 1-minute resolution is carried out throughout a daily analysis. The number of customers that are compliant with the British Standard EN50160 and the number of tap changes are used as key metrics.

The paper is structured as follows: section II presents the modelling aspects of the LV network under study, including the adopted load and PV profiles, and the OLTC-fitted transformer. Section III presents the methodology of the voltage control approach with remote monitoring. In section IV, the control approach is then applied to a real UK LV network using the stochastic analysis. The results are discussed in section V. Finally, the conclusions are drawn in section VI.

\section{NETWORK MODELLING}

\section{A. Real UK LV Network}

A 400V LV network with 351 customers and located in the North West of England is studied in this work. Its topology is shown in Fig. 1 where the yellow triangle represents a 500kVA transformer supplying six feeders. There are 49, 21, $30,100,68$ and 83 customers in each of the six feeders (from feeder 1 to 6), respectively. The network is modeled considering the three-phase four-wire nature of the LV network and with single-phase connected customers.

\section{B. Load and Photovoltaic Profiles}

Realistic load and PV generation profiles were produced using the tool developed in [7]. These high granularity (one

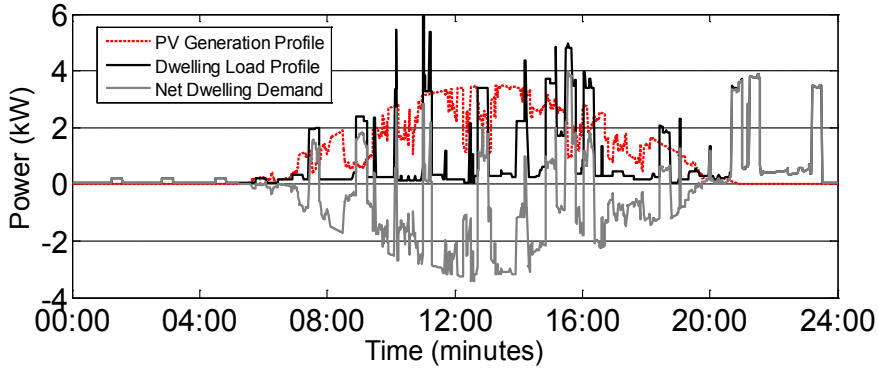

Fig. 2 Daily (weekday, July) profile of net electricity demand for a house ith 2 occupants

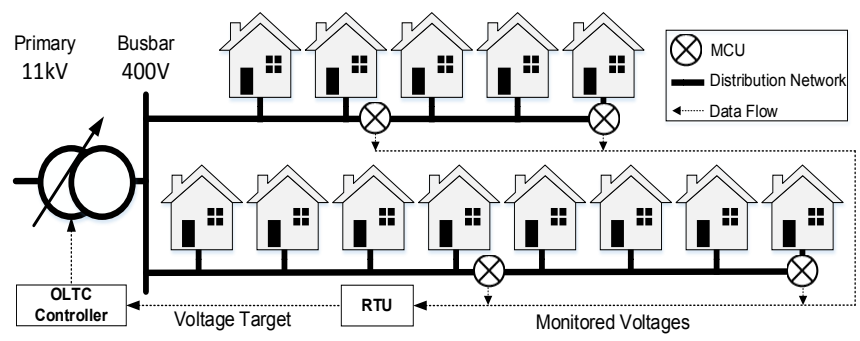

Fig. 3 Remote Monitoring Architecture

minute) profiles consider number of occupants, type of day, and seasonality. The distribution of the load profiles among the 351 customers was based on UK statistics where the proportion of houses with 1, 2, 3 and 4+ persons is $29,35,16$ and $20 \%$, respectively [8]. Fig. 2 shows a daily (weekday, July) profile of electricity demand for a dwelling with 2 occupants. A $3.5 \mathrm{kWp}$ PV panel is considered to be installed in the same dwelling. The corresponding generation and net demand are also shown.

\section{Transformer and OLTC}

A real OLTC-fitted transformer is modeled here considering the transformation ratio of $11 \mathrm{kV}$ to $433 \mathrm{~V}$ (UK practice). The OLTC is considered to have a range of $+/-8 \%$ with $2 \%$ per tap, i.e., 9 tap positions in total (as adopted in the ENWL LoVIA trial project [9]).

\section{Voltage CONTROL With REMOTE MONITORING}

\section{A. Architecture}

A simple schematic of the proposed monitoring and control architecture is shown in Fig. 3. Metrology and communication units (MCUs) are installed at the middle and far end of the LV feeders (considered to be critical points). The MCUs send monitoring data to the remote terminal unit (RTU) located at the LV substation. Thereafter, the RTU is able to obtain all the voltage and current data from the feeders.

The RTU is, in this case, the physical device in which any control logic is coded. Based on this logic, the RTU can then send to the OLTC controller a command to produce a busbar voltage that ultimately alleviates any potential issue.

\section{B. Control Logic}

The control logic proposed in this paper is based on the control algorithm presented in [10]. Some modifications to the logic have, however, been made to allow control actions taken before a voltage violation occurs. An estimation check is also included to prevent control actions that might cause additional 


\section{Accepted Paper}

voltage problems. The control logic considers the voltage target at the busbar as well as the voltages at remote points of the feeders. It essentially calculates the voltage at the busbar required to bring voltages along the feeders within the statutory limits. This calculated voltage corresponds to the target to be sent to the OLTC controller.

At every control cycle the monitored line-to-neutral phase voltages $\left(V_{a}, V_{b}, V_{c}\right)$ at the remote points of the feeders are collected. Then, the maximum and minimum values of the three phases are found $\left(V_{\min }, V_{\max }\right)$. The two values are then checked if they are within the safe or action zones as shown in Fig. 5. In order to quantify the safe and action zones a reference voltage level $\left(V_{\text {reference_level }}\right)$ is considered. The $V_{\text {reference_level }}$ is parameter that can be tuned according to the DNO requirements. For the simulations carried out in this work, the reference voltage is considered to be 1.02p.u. (average of the UK voltage limits).

The bandwidths of the safe and action zones can also be adjusted according to the DNO requirements. However, in this analysis, the safe zone bandwidth is considered to be $+/-4 \%$ of the reference voltage. Any value outside the safe zone bandwidth is considered to be in the action zone.

Therefore, if both values, $V_{\min }$ and $V_{\max }$, are within the safe zone, as illustrated in Fig. 5(a), then no action is taken and the controller proceeds to the next control cycle. If, however, any of the two values is within the action zone (as shown in Fig. 5(b)), then their difference from the $V_{\text {reference_level }}$ is calculated.

Having calculated the two voltage differences ( $\left.V_{\text {max_difference }}, V_{\text {min_difference }}\right)$ from the voltage reference level, their average is then calculated ( $\left.V_{\text {average_difference }}\right)$. With the average voltage difference, the new voltage target $\left(V_{\text {new_target }}\right)$ can then be computed using (1).

$$
V_{\text {new_target }}=V_{\text {curent_target }}+V_{\text {average_difference }}
$$

Before the new voltage target is sent to the OLTC controller a check is carried out to ensure this setting will satisfy the EN50160 voltage limits, 0.94 p.u $\leq V_{\text {new_target }} \leq 1.1$ p.u. If not, the corresponding value is set to its nearest limit. A final check is also performed to estimate the resulting voltage at each of the remote monitoring points due to the new voltage target. The estimated voltages are calculated using (2).

$$
V_{\text {monitored_sense }}=\frac{V_{\text {new_target }} \times V_{\text {monitored }}}{V_{\text {current_target }}}
$$

If any of the estimated voltages at the monitoring points is found to violate the statutory voltage limits then the voltage target is not changed and the controller proceeds to the next control cycle. Otherwise, the new voltage target is sent to the OLTC controller. A flowchart for this logic is shown in Fig. 4.

\section{CASE STUDY}

In this section, the control logic is applied to the LV network presented in section II for different uneven PV penetration levels per feeder (from 0 to $100 \%$ of customers with PV panels). The performance of the control logic is

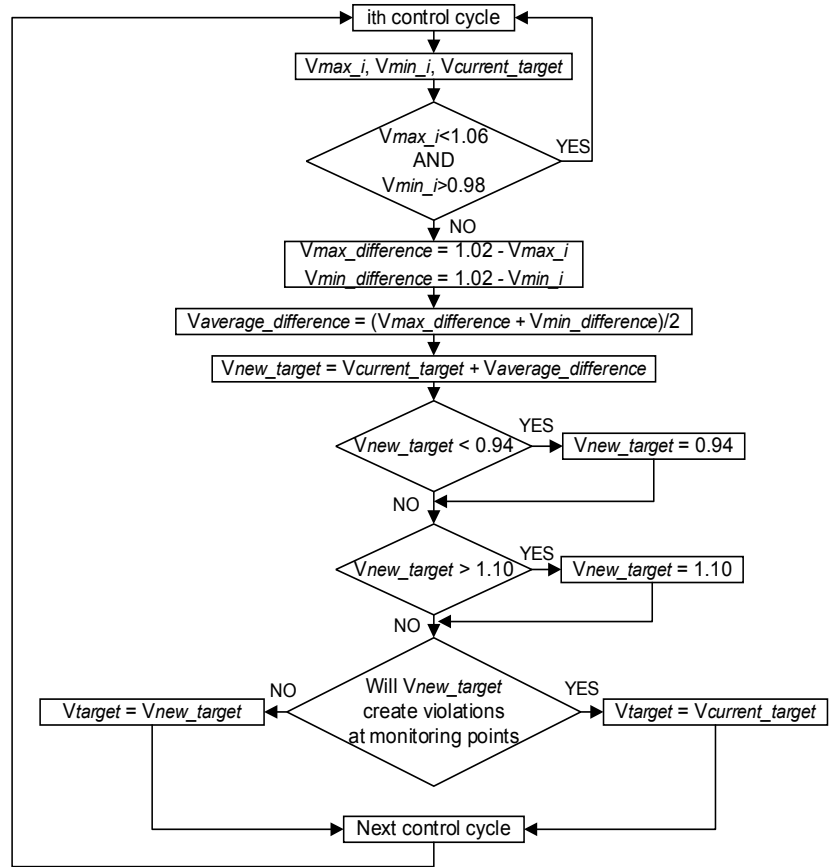

Fig. 4 Control logic

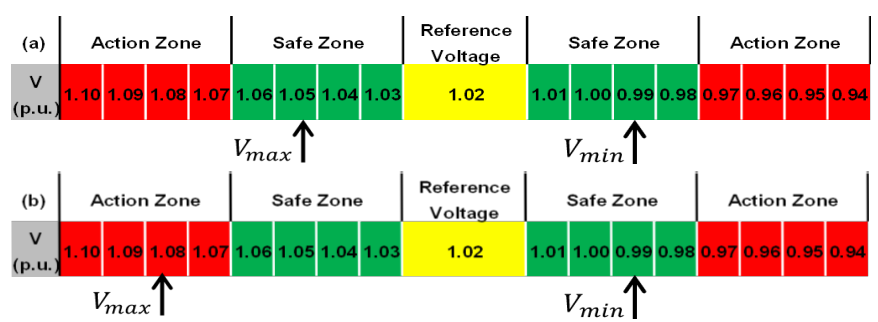

Fig. 5 Safe and Action Zones: (a) not taking action, (b) taking action

investigated for 3 different remote monitoring schemes (i.e., middle, end and middle \& end points of each feeder) and 4 different control cycles (i.e., 1, 10, 20, 30 minutes). Load profiles for each customer are randomly selected from a pool of 1000 profiles considering UK household statistics.

The PV panels are randomly allocated in the network by randomly selecting a feeder and then a customer. This process is repeated until the selected PV penetration level is achieved (percentage of houses having PV systems installed). By adopting this allocation approach, the penetration of PV systems per feeder is considered as uneven (i.e., one feeder can have a higher PV penetration than another one), resulting in more realistic scenarios. The rating of all PV panels is assumed to be $3.5 \mathrm{kWp}$ (aligned with the UK Engineering Recommendation G83 [11]), sharing the same generation profile. For this investigation, only voltage issues are considered. Other technical issues such as cable or transformer congestion are not considered.

To assess the effectiveness of the investigated monitoring and control cycle schemes, compliance of customer voltages (at the connection point) is checked considering the British Standard EN50160 [12] for each 24-hour simulation. According to this standard, and in the UK context, during normal conditions, line-to-neutral voltages must be between 


\section{Accepted Paper}

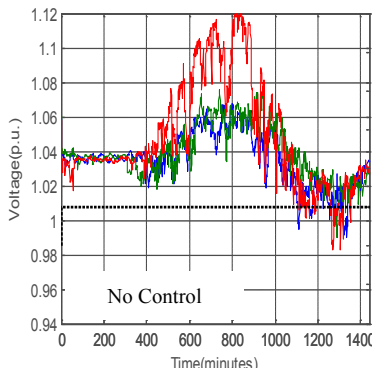

(a)

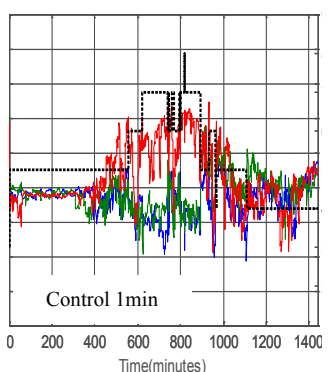

(b)

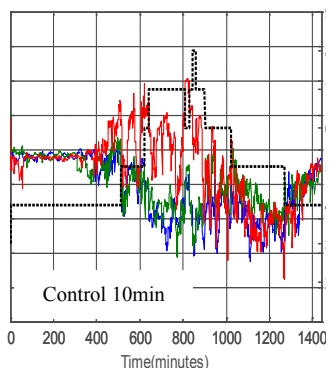

(c)

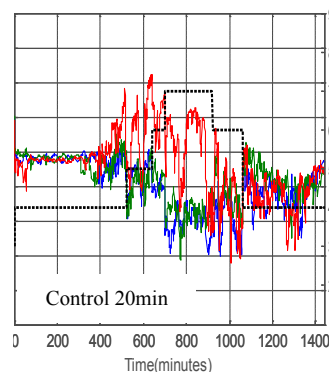

(d)

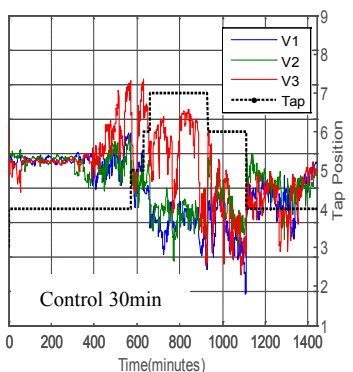

(e)

Fig. 6 Daily voltage profiles at the far end of the feeder 4 considering $70 \%$ of PV penetration (weekday, July) - (a) Without Control and with Control considering (b) 1 minute, (c) 10 minutes, (d) 20 minutes and (e) 30 minutes control cycle

0.9 p.u. and 1.1 p.u. for at least $95 \%$ of data measured in a week (10-minute average rms values), and never outside 0.85 p.u. and 1.1 p.u. The control logic was implemented in MATLAB and the time-series power flow simulations in OpenDSS [13].

\section{A. Deterministic Analysis}

To demonstrate the control actions of the proposed logic, three-phase power flow simulations were carried out on the studied LV network assuming 70\% of PV penetration level (weekday in July, summer) with remote monitoring points at the end of each feeder and also considering four different control cycles. When the network is operating without any control, 22 and 2 customers in feeders 4 and 5, respectively, are not compliant with the BS EN50160 standard. These feeders have the largest number of customers and hence much higher reverse power flows, which causes the voltage to rise above the upper limit. The daily voltage profile monitored at the end point of feeder 4 for the case without control is shown in Fig. 6(a).

Nevertheless, when the OLTC control logic is applied none of the customers experiences voltage problems for all the investigated control cycles. Taking as an example the case of 1-minute control cycle (Fig. 6(b)), it can be noticed that during the period where voltage is rising, taps go up so the voltage target is lowered in order to keep the remote voltages within the limits. The opposite action occurs when remote voltages are below the lower limit.

The influence of different control cycles on the number of tap changes can be visualized in Fig. 6(b), (c), (d) and (e). It is clear that with higher control cycle lengths the number of tap changes is reduced.

\section{B. Monte Carlo Analysis}

One hundred simulations, each representing a day in July, are performed on the studied LV network in order to capture the stochastic nature of demand and generation. The influence of different remote monitoring points and control cycle lengths on the performance of the OLTC control logic is also investigated. The analysis is performed considering different uneven PV penetrations per feeder $(0-100 \%)$, different monitoring points (i.e., middle, end, middle $\&$ end points) and different control cycles (i.e., 1, 10, 20, 30 minutes).

Fig. 7 summarizes the performance of the proposed OLTC control logic on the corresponding LV network for different
PV penetrations. The left-hand side figures present the average number of BS EN50160 non-compliant customers for each penetration level, monitoring scheme, and control cycle. The right-hand side figures show the corresponding number of tap changes triggered by the different combinations of monitoring schemes and control cycles.

When no voltage control is applied (blue line), customers start facing voltage problems at $40 \%$ of PV penetration. Two customers (in average) in the network could be affected at $40 \%$ PV penetration. As the penetration of PV increases, the number of non-compliant customers also increases, reaching the total number of 10 and 55 non-compliant customers when considering 70 and $100 \%$ of PV penetrations, respectively. However, the number of voltage issues is reduced significantly for all PV penetrations when the OLTC control logic is applied. Indeed, by applying the control logic it is possible to increase the PV hosting capacity from 40 to $60 \%$ of penetration level (i.e., without voltage issues).

The results also show that the performance of the proposed control logic is influenced by the location of monitoring points and the length of control cycles. This is discussed below.

1) Influence of remote monitoring points: The results from Fig. 7 demonstrate that the control logic performs better with remote monitoring at the end and middle $\&$ end of each feeder. This is due to the increased visibility which in turn allows a more accurate calculation of the required voltage target. For instance, at $100 \%$ of PV penetration the case with monitoring only at the middle of each feeder resulted in an average of 8 non-compliant customers more than the cases with end and middle \& end monitoring. Nonetheless, given that the latter approaches have similar (average) performances, the end monitoring can be considered as the most costeffective approach to support the operation of the OLTC.

2) Influence of control cycles: The control cycle can influence the number of non-compliant customers but mostly the number of tap changes. Considering the results shown in Fig. 7 using only monitoring at the end of each feeder, the number of tap changes was decreased significantly with longer control cycles. For example, 1-minute control cycles lead to an average of 10 and 80 tap changes for 0 and $100 \%$ of PV penetrations, respectively. These figures are reduced to 0 and 10 , respectively, when a 30 -minute control cycle is adopted. However, given that the number of non-compliant customers 

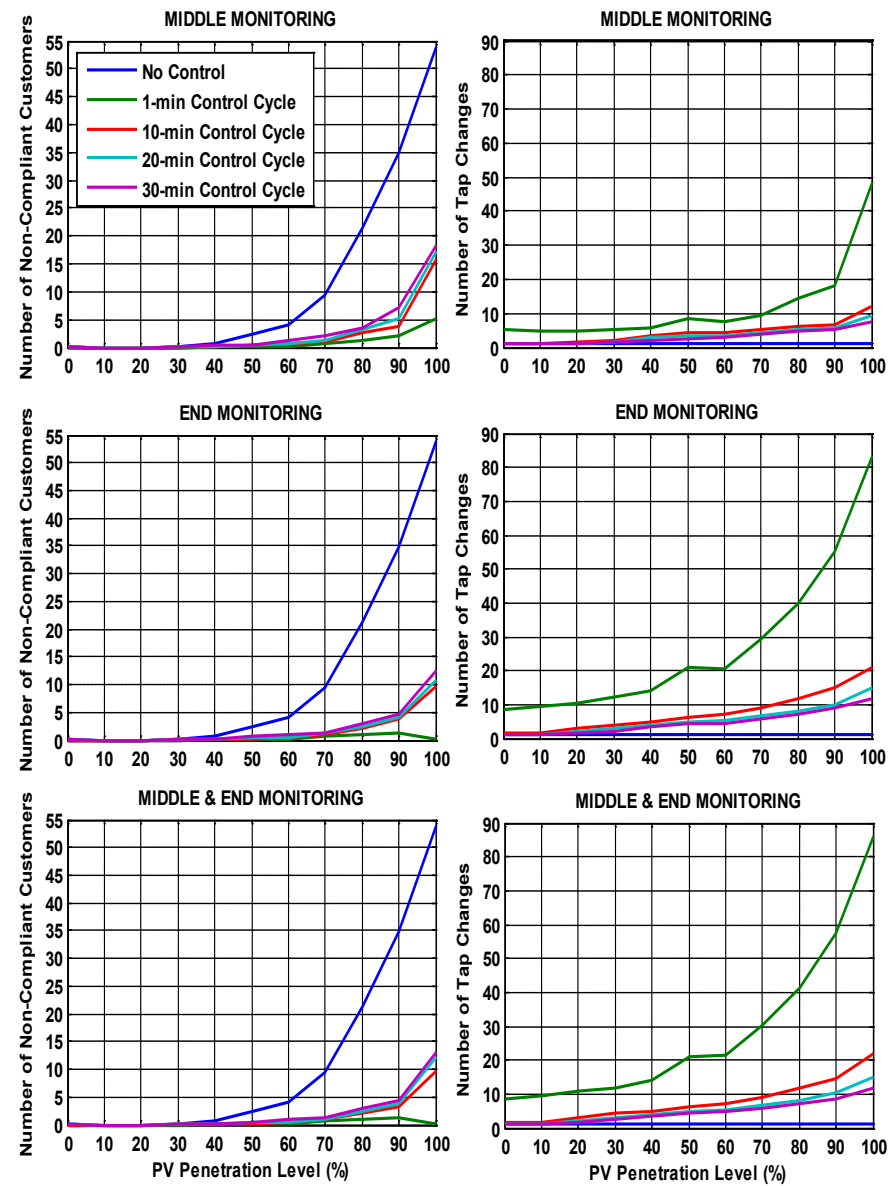

Fig. 7 OLTC Control Logic Performance

increases slightly, a compromise has to be found based on the requirements of the DNO. Consequently, the 30-minutes control cycle can be considered as a trade-off control setting between number of tap changes and non-compliant customers.

\section{DISCUSSION}

This work focused on multiple summer daily scenarios (different demand and PV profiles) given that they could result in higher technical impacts. However, to better assess the performance of the control logic and the influence of different monitoring points and control cycles, multiple seasons should also be investigated so as to produce a more meaningful year-long performance analysis.

The performance of the proposed control logic was assessed considering at least one remote monitoring in each feeder. Scenarios and control schemes with even less remote monitoring should be considered as it is crucial to understand the extent to which limited visibility can be used to adequately manage voltages in LV networks.

\section{CONCLUSIONS}

An OLTC control logic is proposed to manage voltages in LV networks with high penetrations of domestic-scale photovoltaic systems. Crucially, the performance of this logic is assessed considering three monitoring schemes (middle, middle \& end, end of the feeders) and four control cycles (1, 10,20 and 30 minutes) are investigated on a real UK LV distribution network. A Monte Carlo approach is adopted to cater for the stochastic nature of demand and PV profiles (e.g., size, location, behavior).

The analysis highlighted that the location of remote monitoring points in the feeders and the control cycle length play an important role in the performance of the control logic. The results demonstrate that by having monitors only at the end of each feeder and adopting 30-minute control cycles can be a cost-effective approach (i.e., less monitoring devices) to limit tap operations (i.e., less impact on the OLTC utilization) while minimizing the number of customers that could be affected by voltage issues.

\section{ACKNOWLEDGEMENT}

The authors would like to thank Electricity North West Limited (ENWL), UK for the data provided for this work.

\section{REFERENCES}

[1] A. Navarro, P. Mancarella, L. Ochoa, and D. Randles, "Impacts of Photovoltaics on Low Voltage Networks: A Case Study for the North West of England," presented at the 22nd International Conference on Electricity Distribution CIRED 2013, Stockholm, 2013.

[2] Y. P. Agalgaonkar, B. C. Pal, and R. A. Jabr, "Distribution Voltage Control Considering the Impact of PV Generation on Tap Changers and Autonomous Regulators," Power Systems, IEEE Transactions on, vol. 29, pp. 182-192, 2014.

[3] P. Esslinger and R. Witzmann, "Regulated distribution transformers in low-voltage networks with a high degree of distributed generation," in Innovative Smart Grid Technologies (ISGT Europe), 2012 3rd IEEE PES International Conference and Exhibition on, 2012, pp. 1-7.

[4] C. Korner, M. Hennig, K. Handt, and R. Schmid, "Gaining experience with a regulated distribution transformer in a smart grid environment," in Integration of Renewables into the Distribution Grid, CIRED 2012 Workshop, 2012, pp. 1-4.

[5] A. Einfalt, F. Zeilinger, R. Schwalbe, B. Bletterie, and S. Kadam, "Controlling active low voltage distribution grids with minimum efforts on costs and engineering," in Industrial Electronics Society, IECON 2013 - 39th Annual Conference of the IEEE, 2013, pp. 7456-7461.

[6] A. Navarro, L. F. Ochoa, and D. Randles, "Monte Carlo-based assessment of PV impacts on real UK low voltage networks," in Power and Energy Society General Meeting (PES), 2013 IEEE, 2013, pp. 1-5.

[7] I. Richardson and M. Thomson. (2011). Integrated domestic electricity demand and PV micro-generation model. Available: https://dspace.lboro.ac.uk/2134/7773

[8] "Families and Households, 2013," ed. UK: Office for National Statistics, October 2013.

[9] Ofgem and ENWL. (2013). Low Voltage Integrated Automation (LoVIA), ENWL. Available: https://www.ofgem.gov.uk/publicationsand-updates/first-tier-project-registration-proforma-enwt1004-lowvoltage-integrated-automation-lovia

[10]A. Procopiou, C. Long, and L. Ochoa, "Voltage Control in LV Networks: An initial Investigation," presented at the IEEE ISGT EU 2014, Istanbul, 2014.

[11]O. D. E. N. Association, "Engineering Recommendation G83 - Issue 2," in Recommendations for the Connection of Type Tested Small-scale Embedded Generators (Up to $16 \mathrm{~A}$ per Phase) in Parallel with LowVoltage Distribution Systems, ed. UK: Energy Networks Association, 2012.

[12]E. C. Institute, "Standard EN50160 - Voltage characteristics of electricity supplied by public electricity networks," ed: Leonardo Energy, 2013.

[13]R. C. Dugan, "The Open Distribution System Simulator (OpenDSS)," Electric Power Research Institute2013. 